\title{
Breath psychotherapy
}

\author{
Stephen D. Edwards' \\ Department of Psychology, University of Zululand, Private Bag XI00I, KwaDlangezwa, 3886, South Africa \\ sdedward@telkomsa.net
}

\begin{abstract}
Breath psychotherapy is an approach that makes direct use of the breath in healing. There are many forms of breathbased healing: basic breathing and relaxation methods, with or without the practice of psychological skills such as imagery, centring and concentration; expressive physical and emotional techniques; advanced meditation, prayer and other spiritual exercises. Such an approach has been extolled for millennia in the form of various spiritual, wisdom and healing traditions, including ancestor reverence, Judaism, Hinduism, Buddhism, Taoism, Christianity, and Islam which have holistically equated breath, consciousness, energy and spirit, as well as viewing breath as the vital link between body and mind. This approach distils into a perennial psychology, which recognizes a pre-reflective unity underlying and interlinking the various traditions and forms of breath-based healing and therapy. Accordingly, breath psychotherapy is based on an understanding and healing of the total psyche in the original, holistic meaning of this term. The present article is an appreciative inquiry into more recent forms of breath psychotherapy as promoted and used by modern authors and practitioners.
\end{abstract}

Key Words: Breath-based, psychotherapy, breath therapy, consciousness, spirituality, healing.

\section{Introduction}

Over a hundred years ago, a founding father of modern scientific psychology, William James, remarked that the stream of consciousness was only a careless name for what, when scrutinised, revealed itself to consist chiefly in the stream of his own breathing (James 1890). A widely travelled man, James was distilling thousands of years of knowledge of breath psychology stemming from the great spiritual, wisdom and healing traditions, as exemplified through African ancestral breathing (umoya) and the following words of BKS lyengar.

"We give many names to God even though He is One. The same is true of energy. There is nuclear energy, electrical energy, muscular energy and mental energy. All these are vital energy or life energy, called in Sanskrit, pranic energy or simply, prana. Prana is called Chi in China and $K i$ in Japan. Some suggest that the nearest traditional concept of prana in the West is the Holy Spirit of Christianity, a sacred power that is both immanent and transcendent ... Prana is usually translated as breath, yet this is only one of its many manifestations. According to the Upanishads, it is the principle of life and consciousness. It is equated with the soul (Atman). It is the breath of life of all beings in the universe. They are born through it and live by it, and when they die their individual breath dissolves into the cosmic breath. It is the most essential, real and present feature of every moment of our lives and yet it remains the most mysterious. It is Yoga's job, and especially pranayama's, to enter onto the heart of this mystery. Prana in the form of breath is the starting point ...” BSK lyengar (Light on Life, 2005: 65-66).

Although lengthy, this quotation is valuable for its description of that holistic, integral relationship between consciousness, breath and energy, which becomes particularly apparent during those times and events when some apprehension of the unity, eternity and infinity of the present moment break into ordinary awareness. Such unity experiences typically convey the interrelatedness of everything in the universe, where every part is a replica and/or reflection of the whole. In this context, Wilber's (2000) comprehensive mapping of research into the terrain of mystical experiences, reveals Spirit as both ground and goal in a great nest of inter-being. For example, Spirit is conceived as the interiority of all material phenomena, and psychology becomes the study of the structures, states, modes, developmental, behavioural and relational aspects of consciousness and their manifestations in behaviour such as breathing (Edwards 2008; Loy 2007; Wilber 2000).

Such non-dual reality apprehended in unity experiences becomes the foundation of healing in its original meaning of integrating, transforming and bringing together separate or fractured parts into a new whole. While such healing typically becomes more immediately apparent during peak experiences, meditation, prayer, birth, sex and death, as lyengar points out, it is also the most essential, real and present feature of every moment of our lives. For millennia the major spiritual, wisdom and healing traditions, including ancestor reverence, Judaism, Hinduism, Buddhism, Taoism, Christianity, and Islam have holistically equated breath, consciousness, energy and spirit, as well as viewing breath as the link between body and mind. Except for a relatively narrow band of Western empiricism, there is broad consensus among diverse approaches that agree on little else, that unity experiences are valuable and can be related to breath.

I. Stephen Edwards, PhD, DEd, is an Emeritus Professor and Research Fellow in the Department of Psychology, University of Zululand, South Africa

Inkanyiso, Jnl Hum \& Soc Sci 20I I, 3(I) 
Acknowledgement of an original reality and morality in non-dual apprehensions is typically accompanied by recognition of a holistic, ethical obligation underlying healing and therapy of integrating rather than dividing, of gathering rather than dispersing this reality. It also implies original recognition of the therapeutic relationship as core catalyst with healers improving Spirit through helping nature to heal itself. This originally meant more focus on facilitating the energy balance and flow disturbed by disease than interfering with the disease itself, with healers typically functioning in their traditional role of therapists (from the Greek therapeia; attendance) in the undivided wholeness of the healing process (Graham, 1990). From a psychotherapeutic perspective this implies healing of the psyche in its original, holistic meaning as the breath, consciousness, energy, soul and spirit of life that leaves a people at death and continues in some other form (Hergenhahn 200I; Edwards 2008; Myers 1992; 1993). It becomes recognised that although the term 'psychotherapy' is European in etymological origin, and more Western than African and Asian in orientation, it reflects a universal process, which is both holistic and specific.

Earlier works provided empirical evidence for the effect of an African breath psychotherapeutic workshop on spirituality (Edwards, 2009a) and explicated a practical, theological, breath based perspective on the Holy Spirit (2009b). It was also noted that conscious breathing practices may be chosen for spiritual, psychological, combined or other reasons (Edwards \& Sherwood 2008). For example, a spiritual choice may be to simply keep the focus on the breath. Should distracting images, feelings or thoughts come to mind, one simply witnesses them before returning to one's breathing. Continued practice, meditation and contemplation reveal Breath, Consciousness, Spirit and/or God. The psychotherapeutic choice is to consciously work through any distractions that arise. This path is similar to Psychoanalytic Free Association in that it allows the inner world to produce insights that transform ongoing experience and behaviour. The essential difference is choice with regard to level of consciousness involved along a spectrum, traditionally described as ranging from matter to body to mind to soul to spirit. Although the term 'breath psychotherapy' ultimately implies holistic forms of breath-based healing and therapy that includes all dimensions of reality, physical, psychological, social, spiritual and ecological, the main theme of the present article is on psycho-spiritual praxis with initial focus on the psychotherapeutic dimension of breath consciousness and/or conscious breathing

This article is a sequel to an earlier one on fundamentals of breath psychology, traced in terms of its origins in the spiritual wisdom traditions and breath-based applications, which included various specific breathing exercises and their related psychological skills such as imagery, centring and concentration (Edwards, 2008). The aim of the present article is an appreciative inquiry into the study and use of the breath in more recent forms of breath psychotherapy as promoted by modern authors and practitioners. In generalised form, appreciative inquiry gives similar recognition to the claims and strengths of any particular approach or author (Cooperrider \& Whitney 2005). It is descriptive and exploratory rather than evaluative. All approaches are viewed as valid, with their different strengths and weaknesses. At a linguistic level, this implies the conscious use of language that does not discriminate against, but rather privileges equally the different approaches, whatever their evidential profiles, validity claims and respective strengths and weaknesses.

This inquiry concentrates on those approaches that are derived from spiritual practises or modern secular equivalents to these practices. It acknowledges, but does not include, a small but significant literature on retraining of breathing that occurs in some forms of cognitive-behavioural therapy that are very specific problem and solution orientated. Such approaches have little to no spiritual basis or implications, and thus do not always open up the practitioner to broader spiritual practices and development. However, it may be argued that acquisition of a tool kit of specific breathing techniques or breath-based, life skills will facilitate both more holistic psychological and spiritual practice if the practitioner does decide to use such retraining for enhancing mindfulness and/or spirituality.

The following simply constitutes a convenient, chronological sample of ten authors whose work provides some indication of the depth and breadth of breath psychotherapy. Although all approach breath psychotherapy from different perspectives; theoretical, conceptual, experimental, clinical, experiential and practical; all focus to some extent on essential themes of breath psychotherapy, namely breath, consciousness, spirituality, therapy and/or healing.

\section{Carl Jung}

Jung's lifetime preoccupation was the development of a psychology that gave proper recognition to spirit as the universal expression of soul and soul as the individual expression of spirit, "a psychology with the psyche - that is, a theory of the psyche ultimately based on the postulate of an autonomous spiritual principle" (Jung 1931: 344).

Jung insisted that the psyche is antecedent and a precondition for humanity (Brooke, 1991:59). The psychological moment in time for this realisation occurred during his visit to Africa and culminated in his experiences of dawn on Mount Elgin in Kenya where the world appeared as a shining temple (Brooke 1991; Burleson 2005). An Elgonyi elder had described and demonstrated an ancient ritual ceremony of going out of the hut in the morning, spitting and blowing 
vigorously on the hands before holding them up to the sun. For Jung this was a sacred offering to the sun, where the spittle and breath represented the life-force and spiritual healing power.

"If they breathe into their hands, breath is wind and spirit-it is roho, in Arabic ruch, in Hebrew ruach and in Greek pneuma. The action means: I offer my living soul to God. It is a wordless acted prayer, which could equally well be spoken; Lord into thy hands I commend my spirit." (Jung |93 I b:72-73).

In his commentary on the Secret of the Golden Flower, Jung (1957) notes that the Chinese alchemical metaphors of 'diamond body' or 'holy fruit' refer to the purified, incorruptible breath-body or spirit-body sought by Taoist adepts in their search for spiritual immortality. For Jung this also covered an essential quest for all humanity of special relevance in the second half of life.

"Psychologically these expressions symbolise an attitude that is beyond the reach of emotional entanglements and violent shocks - a consciousness detached from the world. I have reason for believing that this attitude sets in after middle life and is a natural preparation for death ... Chinese yoga philosophy is based on this instinctive preparation for death as a goal. In analogy with the goal of the first half of life - procreation and reproduction, the means of perpetuating one's physical existence - it takes as the goal of spiritual existence, the symbolic begetting and birth of a "spirit body" or "breath body" which ensures the continuity of detached consciousness" (Jung 1957: 46).

Although he visited India, collaborated with Richard Wilhelm on the Secret of the Golden Flower, recognised that the transformational, healing, whole making processes inherent in Zen Buddhism were similar to individuation processes, introduced Eastern philosophy to the West and found that the rich symbolism of yoga provided "invaluable comparative material for interpreting the collective unconscious" Jung did not apply Yoga methods in or advocate yoga for Western persons. His reasons were the different lines of spiritual development, the much older and more advanced spiritual traditions of the East, greater emphasis on Christianity in the West, the principle that nothing ought to be forced on the unconscious by consciousness with its typical intensifying and narrowing effect, and need for Western civilisation to free itself from its barbarous one-sidedness and gain deeper insight into human nature. Jung identified a lack of concepts in Western psychology for stages of consciousness so clearly described in Buddhist texts and predicted that the West would ultimately produce its own yoga along Christian foundations (Bonadonna 2003; Jung 1936;957)

Jung's self-analysis brought deep insights into the splits within his personal psyche, as well as the related familial, communal and religious conflicts in the collective unconscious (Jung, 1961; Hayman, 1999). His yoga prediction has not come to pass fully as Yoga is popular throughout the Western world today and amalgamations of Christian meditative practice (particularly monastic) and Yoga are beginning to develop. Moreover his method of active imagination to help Western clients make the unconscious conscious and free it from its rigidity essentially uses a form of meditation and imagery recognised in both Yoga and Zen Buddhism. Central to this method is the focus on images arising as archetypes from the collective unconscious. In describing his method of proof for establishing the existence of the archetypes, Jung (1917) described the essential features of active imagination as follows:

"Another source for the material we need is to be found in 'active imagination'. By this I mean a sequence of fantasies produced by deliberate concentration ... the patient is simply given the task of contemplating one fragment of fantasy that seems significant to him - a chance idea, perhaps, or some thing he has become conscious of in a dream - until its context becomes visible, that is to say, the relevant associative material in which it is embedded. It is not a question of the free association recommended by Freud for the purposes of dream analysis, but of elaborating the fantasy material that adds itself to the fragment in a natural manner" (Jung 1917: 49).

Contemporary variations of this method of amplifying imaginative material use expressive techniques through concentrating on breath, inner images, voices, drawing, painting, movement, sculpture and automatic writing. The therapeutic value of the intensity of clients' emotional disturbance related to archetypal energy and the regulating and transcendent influence of the unconscious through creative formulation and understanding is thus given proper recognition and expression. Although care must be taken with the method so as not to unleash a psychosis (as is sometimes the concern in kundalini yoga), once clients have fully confronted and owned disturbing archetypal material, faith, trust and confidence to overcome similar future threats becomes established (Jung 1916; 1917).

\section{Wilhelm Reich}

Wilhelm Reich has only recently received proper recognition for his contributions to breath-energy healing in the West. An Austrian farmer's son, Reich completed a medical degree at the University of Vienna, studied under Freud, was a member of the Vienna Psychoanalytic Society from 192I to 1934, practised psychoanalytical psychiatry, opposed the Nazi party and in 1934 fled to the USA where his research into the role and function of orgone energy attempted to provide some degree of natural scientifically orientated evidence for prana, libido theory and the psychodynamic role played by

Inkanyiso, Jnl Hum \& Soc Sci 20I I, 3(I) 
life-breath-energy. In his "Vegetotherapy" he particularly worked to deepen and liberate breathing in order to improve and intensify emotional experience.

As an analyst Reich had observed that patients held their breath when they were resisting the full and free expression of their thoughts and that flourishing living was related to optimal use of their life-energy in general and sexuality in particular. His kinaesthetic insights into respiratory blocks and muscular armor, which formed a foundation for his later work on character analysis, are clearly apparent in the following psychodynamic perspective on diaphragmatic function in restricting depth of breathing and feeling.

"The reason for this strong resistance against the full pulsation of the diaphragm are clear enough; the organism defends itself against the sensations of pleasure or anxiety that inevitably appear with diaphragmatic movement" (Reich 1949:381).

Reich both somaticised and broadened Freud's libidinal perspective with an holistic approach which gave emphasis to full sexual experience, with health being associated with loving, uninhibited sexual exchange leading to thoroughly satisfying orgasm, not necessarily accompanied by the spirituality of Tantric yogic sexuality. Illness was therefore perceived as directly related to tension through blocked or damned up sexuality, leading to character and body armouring, which required full release in order to establish healing through heightened consciousness and free flowing energy (Dichtwald 1977). Reich's approach echoed some Hindu and Taoist methods and although they may vary in philosophical underpinning, many modern healing methods such as Bioenergetic analysis, the Alexander Technique, Gestalt therapy, Rolfing and Feldenkraus are direct descendants of his approach.

Tragically, much of Reich's research was ahead of its time, controversial and unacceptable to the USA Food and Drug Administration, who denied the existence of orgone energy and had some of his books burned. This campaign against Reich was instrumental in his eventual imprisonment and unhappy death of heart failure in the Federal Penitentiary in Lewisburg, Pennsylvania. While many of Reich's ideas were useful and influential (e.g. the appreciation of body states), the orgone energy work has at the most received minimal, fringe acceptance (and some explicit rejection, as shown by the famous collaborative experiment Einstein did with Reich, with Einstein eventually rejecting the idea because there was a plausible alternative explanation). However his legacy continues today through the Internet and such institutions as the Wilhelm Reich Museum at Organon, Maine (http://www.wilhelmreichmuseum.org/biography.html retrieved 4-8-I I).

\section{Alexander Lowen}

Mainstream development and expansion of Reich's work can be traced to Alexander Lowen, a lawyer from New York City, who was Reich's patient in 1942, continued as his student, trained as a psychotherapist, completed a medical degree through the University of Geneva and, with colleague John Pierrakos, founded Bioenergetic Analysis, a specific form of somatic-psychotherapy, based upon the continuity between body and mind. Bioenergetic Analysis is rooted in the work of Wilhelm Reich, yet also echoes Hindu and Taoist energetic understandings as to the linking, psychosomatic function of the breath as revealed in the following quotation:

"Breathing plays an important role in bioenergetics because it is through breathing deeply and fully that can one summon the energy for a more spirited and spiritual life" Lowen (1976: 66).

Lowen (1967) developed various manipulative procedures and special body exercises that have become standard techniques of getting in touch with and releasing body tensions through physical movement. His focus was on correct body alignment in order to allow problematic emotional experience to be released, the breath to flow naturally again through the body and consequently further enhance bodymind functioning. Following Reich's lead in exploring how bodily postures become structurally moulded by psycho-emotional experiences in illness and such emotions as joy, happiness and freedom relate to the free flow of bodily energy, Lowen also recognised the importance of spiritual dimensions for quality of living, stimulating the advent of various models of body-based psychotherapy, all trying to bring about a union of body and mind through the free flow of breath (Lowen 1990; Sherwood 2007).

Body-based psychotherapy is psychodynamic to the extent to which it allows previously avoided movement, feelings and experiences to be re-activated, thus allowing unconscious psychic material to come to light and become accessible for amplification and interpretation. The healing effect is thus based upon new opportunities for processing early experience, making possible their re-evaluation, completion and therapeutic integration through the mobilisation of healing energy by energetic activation on an immediate body level. Essential techniques in this respect are the deepening of the breathing, and the releasing of tensions by special breathing and muscle release interventions as well as other expressive techniques. Intellectual mental processes are temporarily suspended. Clients' newly gained access to deep emotional experience brings concomitant changes in intellectual and social functioning. In addition, through the practice of grounding, a physically secure but flexible stance improves phenomenological connection with reality and facilitates therapeutic work in all spheres of life; personal, familial and social (Gudat 1997).

Inkanyiso, Jnl Hum \& Soc Sci 20I I, 3(I) 
Morningstar (1999) has advanced bioenergetic analytical breathwork, through his method of focus on the unique nature and wellness component of each type as in the following examples. Persons with Psychic Sensitive patterns associated with birth are encouraged to breathe freely, through unlocking their chests, giving vent to fear and rage, and expressing their artistic sensitive natures. Those with Empathic Nurturing patterns associated with issues of deprivation and abandonment in the first year of life are encouraged to find their true source within, to share empathy and give out love. Persons with Inspirational Leader patterns acquired in the first three years of life are encouraged to exhale, feel pleasure in vulnerable feelings and let go appropriately with others. Those with Steadfast Supportive patterns developed in their second to fourth years are assisted to exhale their experience of being under continuous pressure to please, so as to easily and comfortably stay with challenges and help others. Persons with Gender Balanced patterns acquired during their third to fifth year are encouraged to balance the inhale and exhale, feminine and masculine, vulnerability and strength. Energetic Grounded types overcome disappointments in intimacy and associated body armouring in back and torso regions through focus on integrating exhale and inhale, heart and genitals.

\section{Stanislov Grof}

Stanislov Grof's main research interest has been in the healing potential of non-ordinary states of consciousness. His research into psychedelic states associated with LSD lead to the independent practice of a form of breathwork called holotropic, which from its Greek roots 'holos' and 'trepein' means to 'move toward wholeness.' Inspired by shamanic breathing and rebirthing processes, holotropic breathwork comprises five elements: group process, rapid breathing or hyperventilation, evocative music, focused body work, and expressive drawing. This breathwork is usually done in groups, with pairs of persons taking turns as breather and supporter. Trained facilitators are also available to help if necessary. The general effect is an amplification of experience followed by healing, which is especially related to body, personal unconscious, birth process and transpersonal categories of experience (Grof 1988).

Grof and Bennett (1992) distinguished four stages of rebirthing; the amniotic universe of the womb, usually associated with blissful feelings of peace and joy in a healthy womb; cosmic engulfment and disturbance associated with contractions, which are related to an unbearable feeling of being stuck in hell with no way of escaping; the death versus rebirth struggle of the second clinical stage of childbirth with its intense struggle for survival and finally the death versus rebirth experience associated with intense ecstatic feelings of liberation and love as a new world begins. It has been hopothesised that holotropic breathwork operates via a biopsychological mechanism that results in experiential exposure to feared internal representations, extinction of covert avoidance behaviors and consequent catharsis (Rhinewine \& Williams 2007).

Although many participants have attested to the healing qualities of holotropic breathing, others have found the method unnatural, artificial and intrusive. Grof (1988) himself observed that emotional and psychosomatic distress can develop, for which continued breathing usually brings good resolution. Disturbances include violent shaking, grimacing, coughing, gagging, vomiting, a variety of movements, and a wide range of sounds that include screaming, baby talk, animal voices and talking in tongues or a foreign language. In some cases, focused body work such as massage and acupressure is needed. Contraindications include: serious cardiovascular problems, glaucoma, previous psychiatric illness, pregnancy and epilepsy.

Holotropic breathwork has elicited various critical commentary in relation to: the necessity of regressing to the perinatal state to resolve birth trauma; professional concerns that hyperventilation can cause seizures or precipitate psychosis in vulnerable persons; the view that inspirational shamanic breathing methods can only be correctly understood in the context of their original cultures and the motives and wisdom of facilitators providing holotropic breathwork in a commercial context has been questioned. Grof $(1998 ; 2003)$ has disputed many of the medical criticisms, arguing that they are based on misunderstandings of the physiological and psychological processes involved. He has stressed the adventurous nature of the method and concludes that rapid breathing is not in itself a pathological phenomenon and that with skillful support and guidance, the emergence of symptoms can result in healing of emotional and psychosomatic problems.

\section{Deepak Chopra}

Breath based psychotherapy has reached humanity on a large scale through Deepak Chopra's many popular, best selling books, based on an approach which combines modern quantum theory with traditional Ayervedic and yogic healing. Although the entire book titled Seven Spiritual Laws of Yoga (Chopra \& Simon 2004) may be viewed as breath psychotherapy, the laws relate in particular to the chakra patterns of breath-energy and their harmonious optimisation through kundalini yoga for example. By virtue of their breath-energetic locations from perineum to crown, the chakras muladhara, svadisthana, manipura, anahata, vishudda, ajna and sahasrara are viewed as respectively associated with the

Inkanyiso, Jnl Hum \& Soc Sci 20I I, 3(I) 
laws of karma, lest effort, intention and desire, giving and receiving, detachment, insight and intuition, and pure potentiality. An example of the Law of Giving and Receiving follows.

"The Law of Giving and Receiving is in continuous play during the practice of pranayama breathing exercises. Conscious breathing means focusing your attention on the perpetual exchange that is taking place between your personal body and the extended body of your environment. You exchange ten billion trillion atoms with your surroundings with every breath you take. The atoms you inhale every day have traversed the bodies of living beings across the universe and across time. Within you right now you have carbon atoms that once inhabited the body of a Cheetah in Africa, a dolphin in the South Pacific, a palm tree in Tahiti, or an Australian Aborigine. Ultimately every particle in your body was stardust, created at the dawn of the universe. Your breathing is a continuous testimony to the Law of Giving and Receiving" (Chopra \& Simon 2004:103).

Although there is no substitute for proper mentoring by a qualified yoga instructor, and other authors such as Judith (2004) have provided greater theoretical depth and detailed individual templates for each chakra, Chopra and Simon's book is an excellent self-help source with the general public being provided clear instructions for conscious breathwork and energy management through pranayama in the form of various breathing exercises in relation to the throat, chin and root locks; moola bandha, uddiyana bandha and jalandara bandha.

\section{Edward Bynum}

Edward Bruce Bynum, Director of the Behavioural Medicine Program at the University of Massachusetts Health Services is an African-American practitioner of Kundalini Yoga, who deserves special mention for promoting breathwork in relation to psi in two particular books, the Family Unconscious and the African Unconscious, which explicates the family collective unconscious and family behavior in documented case histories of telepathy, clairvoyance and second-sight. The African Unconscious presents in detail a unifying and healing vision of our deeper shared identity as a human species from our earliest days on to contemporary times. It links both modern and ancient psychology with the great enduring spiritual traditions in an inclusive future vision. Further excellent supportive theory for Bynum's work has been provided by Linda Myers (1993) from Ohio State University in her excellent book Understanding an Afrocentric World View: Introduction to a Optimal Psychology, which proposes a model of human functioning consistent with insights into that immanent and transcendent consciousness, which emerges from the interior moving, energetic, spiritual ground of all material existence, as explicated in the wisdom tradition of African deep thought, modern physics and Eastern philosophies (Bynum 1984, 1999; Myers 1993).

Bynum's breath psychotherapeutic writings are valuable for their explication of the ability of breathing techniques to increase awareness, co-ordination and control of the autonomic nervous system. For example as each inhalation stimulates the sympathetic system, and each exhalation stimulates the parasympathetic system allowing control, skilled practitioners first learn to gain increasing control over the autonomic nervous system, heart and brain functioning through regulating arousal levels, then exploring different levels of awareness ranging from denser to finer, increasingly subtle levels of body-mind consciousness in pre-personal, personal, interpersonal, familial, communal and wider transpersonal contexts.

\section{Daniel Reid}

Daniel Reid $(1989,1993,1998,2003)$ is a best selling author who deserves special mention for his role in communicating Taoist breathwork to a wider world readership. Born and educated in America, Reid studied Asian philosophy and lived in Taiwan for many years, where he studied and practised under Taoist masters, while researching and translating ancient and original sources. In the book Chi-gung (Reid 1998) he provides an inspired account of Taoist emphasis on movement and change based on the notion of dynamic patterns, continually forming and dissolving in the cosmic way of the Tao as exemplified in the I Ching (Book of Changes). Chi-gung is an ancient Chinese system of cultural therapeutics with medical, martial and meditative implications. Chi means breath and air and by extension, energy and vitality. Gung means work, skill or practice. Hence chi-gung refers to breathing exercises or energy work, based on the subtle skill of breath control. The word chi was used in ancient China, thousands of years ago to denote the vital breath or energy animating the entire cosmos and thereby predicting the discovery, in modern quantum physics, of the dynamic interrelatedness and continuous interactions between form and void, as particles condense, dissipate, collide and transform (Reid 1998).

Basic ways of moving energy through chi-gung include the following. Shi-chi (assimilating energy) involves drawing in chi through various vital energy gates and or chakras. Shing-chi (circulating energy) clears blockages, balances and harmonises energy in channels and meridians. Pai-chi (expelling energy) as in bellows breathing for example, cleanses the system of stagnant or toxic energy. Huan-chi (exchanging energy) refers to recharging one's human batteries through breathing exercises, which intermingle one's energy with pure forms found on high mountains or at the sea. Yang-chi 
(cultivating energy) is a practise that stores energy in the lower abdomen or other organ energy systems. Lien-chi (refining energy) typically involves meditation, as in kundalini yoga, where evolutional energy is slowly drawn up the spine. In an internal analogue of external alchemy, whereby solids are transformed into liquids then gases, essence into energy into spirit, Hua-chi (transforming energy) is the basic mode of changing bodily fluids into mental energy through breathing exercises. Fa-chi (emitting energy) is used by energy healers, typically through the lao-gung points in the palms of the hands (Hiew \& Yap 2005; Reid 1998).

Besides emitted healing by energy healing masters Chi-gung is a marvellous form of self-care energy medicine to prevent illness and promote health. It basically consists of still and moving forms such as microcosmic circuit meditation and tai-chi respectively. In contrast to standing and moving forms (macrocosmic orbit, which include tai-chi) microcosmic orbit meditation refers to a still sitting form of meditation where energy is circulated through intentional imagery and focussed breathwork along governor and conception channels of the meridian system. Microcosmic orbit meditation is similar to Kundalini yoga. Reid (1998) has described the process as a form of internal alchemy where the three treasures of essence, energy and spirit and their external equivalents of body, breath and mind, located in the lower (under the navel), middle (solar plexis) and upper elixir fields (brain) are nurtured and transformed into that spiritual realm of pure radiant energy, whence we all came and will return.

As a form of health promotion, deep breathing and continuously moving meditation, Tai Chi, is the single most popular style of chi-gung found throughout the world today (Reid 1998). Tai Chi constitutes a low impact, low to moderate intensity exercise, incorporating elements of relaxation, flexibility, balance, and strength, in a series of continuous breath co-ordinated movements. Exercise features include continuous shifting of weight on left and right feet, with bending and flexion of knees, straight back and neck, trunk rotation and asymmetrical diagonal arm and leg movements, mostly in a semi squat position. The exercise intensity is variable and can be adjusted by the height of the postures, duration of the practise session and training style. It is suitable for all persons of all ages and fitness levels, and can be performed individually or in groups in any setting (Taylor-Piliae \& Froelicher 2004). Recent comprehensive research reviews on chigung and Tai Chi have revealed substantial evidence for illness prevention and health promotion. Findings include significant improvements in aerobic capacity, strength, balance, flexibility, relaxation, mood, cardio respiratory functioning, longevity, blood pressure, osteoporosis, low back pain, arthritis, stress, anxiety, depression, quality of life, psychosocial and immune functioning (Gallagher 2003; Lan Lai \& Chen, 2002, Taylor-Piliae \& Froelicher 2004).

\section{Joy Manne}

Joy Manne deserves special mention for her academic and research role in founding an internet peer-review journal The Healing Breath: a Journal of Breathwork Practice, Psychology and Spirituality to contribute towards the creation of a professional literature of high standards and quality for Breathwork, its Practice, Psychology and Spirituality. On her website Joy writes that the Healing Breath was inspired by the creation of the International Breathwork Foundation and the International Society for the Advancement of Respiratory Psychophysiology. Joy has a PhD in Buddhist Psychology, has practised Vipassana meditation since 1965, was taught by Dhiravamsa and trained in Spiritual Therapy by Hans Mensink and Tilke Platteel-Deur in Holland, 1986-1988. Her excellent article on 'One breath' (Manne 1999) as well as extensive other contributions from joy and other contemporary breath therapists can be found in the Healing Breath Journal at the following website: www. HealingBreathJournal.org (http://www.healingbreathjournal.org/index.htm)

\section{Ken Wilber}

Ken Wilber (1977, 2000; 2007) has brilliantly included the various spiritual, wisdom and healing traditions into a holistic psychology based on an all quadrant all level (AQAL) model of consciousness development, which integrates four quadrants, intentional, behavioural, cultural and social; and all levels of the great nest of Being from matter, to body, to mind, to soul, to spirit; through which run various distinct developmental lines, cognitive, emotional, social, spiritual and so on.

Full continuous knowledge of the original oneness of pre-reflective consciousness becomes inevitably distorted owing to our inhabitation of physical bodies, with brains that have selective filtering and screening functions, producing ordinary dualistic consciousness, perceptions, repressions and projections. Wilber (1977) has defined these dualisms in terms of primary (space, self-other), secondary (time, being vs nonbeing), tertiary (body-mind) and quarternity (shadow) levels of amplifying distortions leading to the perceived diversity of our everyday gross waking levels of consciousness.

Recognition of the eternally infinite present moment of now and here is what Wilber (1977) has termed 'that which is always already'. He notes that while we can say really nothing about this reality, without logic and language polarising and dividing our expressions, it can be experienced through breath-based meditation, where this original reality has been given many names such as void, sunyata, pure pre-reflective consciousness, prana, chi, energy, absolute subjectivity, Inkanyiso, Jnl Hum \& Soc Sci 20 I I, 3(I) 
immanent and transcendent spirituality, Brahmin, Tao, the Godhead and so on. Wilber has described this experience as a paradigmatic function of skilful experiments involving a form of do, discover and decide sequence that he describes as instrumental injunction, intuitive apprehension and communal confirmation or rejection. From this transpersonal base, he has distinguished at least four higher levels of inclusive and transcendent spirituality, which he has respectively termed nature, deity, causal and nondual mysticism (Wilber 1977; 2000).

Wilber (2000: 113) has summarised his essential, integral healing principle as 'exercise body, mind, soul and spirit in self, culture and nature'. This takes into account all levels of the four quadrants of the integral psychology system. The inclusive and transcending functions of breath as and in consciousness development predict transformational effects of breath psychotherapy in all quadrants and at all levels in the great nest of being. For example, although breath-based meditation and breath psychotherapy is subjectively experienced as transformations of individual, subjective levels of consciousness, meditation research has shown how these experiences are intimately related with objective changes in brain chemistry and electricity, as well as social changes if experienced in groups as in the case of mass self-realisation through Sahaja Yoga, thus including all four quadrants of Wilber's model, intentional, behavioural, cultural and social. As well as all quadrants being intimately implicated, the transformational experience reaches from material levels into the highest contemplative states of the traditional samadhis at nondual levels of consciousness (Baijnath 2008; Wilber 2000, 2007).

\section{Patricia Sherwood}

Patricia Sherwood of Sophia College in Australia has pioneered a comprehensive approach to holistic counselling (Sherwood 2007). While the approach is mainly based on Rudolf Steiner's anthroposophical medical model, it also weaves in Husserlian phenomenological, Buddhist, feminist, new age, energetic, expressive therapeutic or other models of counselling. Steiner's spiritual scientific approach is relevant as it integrates Western perspectives with Eastern wisdom traditions in their focus on various forms of breath- energy healing. Steiner distinguished four main energy layers or bodies which surround the physical body; the etheric/health, emotional/astral, mental/I am and causal/I AM energy bodies. It is instructive to examine these interpenetrating energy bodies in relation to both earlier psychology schools of psychoanalysis, behaviourism, humanistic and transpersonal psychology as well as Ken Wilber's writings and maps on integral psychology.

To illustrate the somatic basis of the theoretical model, Sherwood draws on Pert's (1997) psychoneuroimmunological research on the influence of emotion on chemical responses of the body. In practice holistic counsellors encourage clients to breathe consciously and fully into the precise body part that has carried negative energetic imprints from the astral level into the etheric and physical body, experienced in terms of breath constricting trauma. A full range of expressive therapeutic techniques complement this breath-based grounding. By way of example, let us examine the following holistic anthroposophically based trauma counselling model, which has the potential to complement other trauma counselling models and assumes all usual relationship variables, microskills and therapeutic principles involved in trauma counselling are followed prior to the specific counselling sequence.

The model assumes that wherever there are imprints of trauma there are contractions in breathing. These contracted patterns of vibration can also be represented by sounds. Steiner described the role of sound pattern vibrations and proposed the theory that the dynamics of speech sounds provide the structure of the human constitution, with the physical body shaped by consonant forces, astral by consonant sounds, the etheric by vowel forces and the I by vowels. Sherwood has found that the appropriate sounds can release blocks through restoring breath flow by reversing the original breath contraction related to the initial trauma. Hard, earthy consonant sounds "b, d, g, p" are related to physical body trauma. Woody "n, m, ng, mg" sounds echo and express trauma to covering and nurturing tissues between solid and liquid such as ligament, muscle, cartilage and skin. Watery etheric sounds "I, w" most powerfully represent the life force and express liquid flowing gestured and/or emotional blocks. Fire sounds " $f, f h, s, s h, v, h$ ' can be used to warm body and psyche for astral imprints of coldness, abandonment or detachment. Air sounds " $r$ and wh' have an energising and detoxifying effect on physical, etheric, astral and causal bodies. Vowel sounds are particularly valuable for energising and strengthening the $\mathrm{I}$.

Artistic mediums valuable for differential trauma effects to physical, etheric, astral, contracted and expanded l's are respectively: architecture, sculpture, painting, music and poetry, which can be combined with the therapeutic effects of different colour, working with clay, drama, dance and various other physical activities. The essential expressive process involves a dramatic enter-exit-behold sequence. When ready, clients are encouraged to step into the imagined traumatic space, re-experience the breath constriction, gestures and sounds associated with the most recent traumatic experience, step back and describe/gesture the breath block associated with the trauma, then gain perspective on the experience through drawings, movements to shake off the trauma and verbal descriptions of qualities lost, which are then replaced 
with new energetic healing patterns, experiences, qualities, resources, skills competencies, stories and relationships over time. Should the presenting trauma have activated previous traumatic experiences, a similar sequence is enacted for each successive past traumatic experience until the original imprint is removed. Therapeutic creativity is dependent on careful listening, observation and empathic intuiting of the client descriptions of their problems and the solutions needed. A special advantage of the model is its immediate propensity for non-verbal expression as well as pre and post-testing with drawings and or sculptures to leave clear evidence trails for future counselling and research.

The above is only a sketch of a trauma counselling sequence. The Sophia holistic counselling approach, which views breath as our first language and sign of presence in body, mind and spirit, is also concerned with larger and deeper issues. Along with appropriate critical commentary on contemporary humanity's desperate search for meaning in fragmented realities, addictions, consumerism, materialism, narcissism and cynicism, this approach impresses with its therapeutic depth, practical counselling suggestions and specific intervention sequences to prevent, manage, resource, empower and heal the inevitable accompanying panic, anxiety, anger, despair, alienation and other violent shadows of destructive and inauthentic living. At the same time, clear guidance is given of ways to recycle destructiveness into creativity, to reclaim an original birthright of meaning, social justice, personal integrity, flourishing health, moral strength, compassion, respect, love and enduring spiritual living. All of this is based on the premise that the degree to which harmonious consciousness is brought into the body through the primary form of breath, so will physical, mental, social, ecological and spiritual health and well-being be developed.

\section{Conclusion}

Breath psychotherapy refers to the direct use of the breath in the therapy and healing of the psyche. It has its foundations in what may be termed breath psychology, an ancient applied science concerned with the study and use of the breath in all its holistic connotations as implied by the original meaning of the term "psyche" i.e. as breath, soul, spirit, life-energy, consciousness, etc. that leaves a person at death and continues in some other form. The term "therapy" is complementary in its original meaning as attending/serving/caring for a person/society/ecology while allowing healing to take its course in transforming illness, a process of making a person whole again in all ways, physically, spiritually, morally, socially, ecologically, cosmologically, in recognition of the ongoing cyclic interconnectedness of everything, creatures, plants, animals, humans, in life, death, here and hereafter.

The central theme of this article may be concluded with the breath psychotherapeutic recognition that the same nonduality behind all the spiritual wisdom and healing traditions, the unity underlying all the diversity, the Spirit in matter, or to speak more metaphorically, the One Breath that breathes us, animating our everyday existences, underlies all modern healing and psychotherapies. There is recognition that in addition to the many applications of breath psychotherapy, its essence in the form of breath consciousness and/or conscious breathing forms the point of departure for further insights and spiritual development.

Furthermore this perennial theme running through the spiritual healing traditions is explicated and amplified by an appreciative inquiry into contemporary breath psychotherapists and forms of breath psychotherapy. As exemplified in Joy Manne's article, One Breath is the foundation for many modern applications: Jung's image of the breath-body and active imagination; Reich's Orgone energy; Lowen's bioenergetics, grounding and spirituality of the body; Grof's holotropic breathwork; Chopra's explication of prana and the spiritual laws of yoga, Bynaum's exposition of the relationship between breath-energy, psi family and African unconscious; Reid's insights into chi gung sitting and moving forms of breathing exercises and meditation; Wilber's Buddhist inspirations, AQAL model and clarity in mapping higher stages and states of consciousness development and Sherwood's body and breath based, holistic counselling model as well as her detailed, practical interventional sequences in trauma counselling.

As in all holistic forms of psychotherapy where therapists are ultimately working with the soul and spirit of a human being, the need for caution is important in breath psychotherapy, and needs to be continually emphasised. Breath techniques that involve much emotional induction can trigger crises. These are unlike Yogic techniques, in that they are practiced in order to produce an emotional state or emotional release (and thus may produce overwhelming emotional states), while yogic techniques are more about control. These emotional release techniques are more problematic when used in combination with touch, as Reich and Lowen have found in various controversial incidences. Professional ethical conduct, a sine qua non in all authentic and effective forms of psychotherapy, is therefore even more important in any such forms of breath psychotherapeutic practice.

It is hoped that this brief hors d'oeuvres of modern forms of breath psychotherapy and authors will serve to further promote breath psychotherapeutic theory and practice. All authors contributions and in particular Jung's images and Wilber's mapping models create space for recognition of Spirit-Breath as intrinsic context for harmonious Inter-being. In the sense that ever more meaningful inspirations, exhalations, psychotherapeutic interventions, personal, social and Inkanyiso, Jnl Hum \& Soc Sci 20I I, 3(I) 
ecological harmony may be realised through ongoing, diligent practise, breath psychotherapy may be regarded as one vital and necessary therapy for future universal health and wellbeing.

The practice of breath based meditation, contemplation and breath psychotherapy continually remind us that there is 'oneness from the word go'. It is simply a matter of returning to the Source, to the spiritual ground that forms the context for all our endeavours, of continually reclaiming our heritage, which was already there from the beginning. T.S. Elliot in "Little Gidding" provides one description of both the experiential journey and the breath psychotherapeutic moment of arrival in the immortal lines.

We shall not cease from exploration

And the end of all our exploring

Will be to arrive where we started

And know the place for the first time.

\section{References}

Baijnath, P. 2008. Sahaja yoga: therapeutic community. Unpublished doctoral thesis. KwaDlangezwa: University of Zululand.

Bonadonna, R. 2003. Meditations impact on chronic illness. Holistic Nursing Practice, November/December, 309-3 I9.

Brooke, R. 199I. Jung and phenomenology. London: Routledge.

Burleson, B.W. 2005. Jung in Africa. New York: Continuum.

Bynum, E.B. 1984. The family unconscious. Wheaton, III: Quest Books.

Bynum, E.B. 1999. The African unconscious: roots of modern psychology. New York: Teachers College Press.

Chopra, D. \& Simon, D. 2004. The seven spiritual laws of yoga. Hoboken, New Jersey: Wiley and Sons, Inc. Cooperrider, D.L. \& Whitney, D.K. 2005. Appreciative inquiry: a positive revolution in change. CA San Francisco: Berrett-Koehler.

Dychtwald, K. 1977. Bodymind. NewYork: Pantheon.

Edwards, S.D. 2008. Breath psychology: fundamentals and applications. Psychology and Developing Societies, 20 (2), I 3 I-I64.

Edwards, S.D. 2009a. The description and evaluation of an African breath psychotherapeutic workshop. Journal of Psychology in Africa, 19(2), 253-260.

Edwards, S.D. 2009b. A breath-based apprehension of the Holy Spirit: practical theological, psychological, phenomenological and contextual perspectives. Practical Theology, 24 (2), 8I-98

Edwards, S.D. \& Sherwood, P.M. 2008. Breath-based Mental Health Promotion. Zululand University: KwaDlangezwa.

Gallagher, B. 2003. Tai chi chuan and qigong; physical and mental practice for functional mobility. Topics in Geriatric Rehabilitation, 19(3), 172-182.

Graham, H. 1990. Time, energy and the psychology of healing. London: Jessica Kingsley.

Grof, S. 1988. The adventure of self-discovery. Albany, N.Y: State University of New York Press.

Grof, S. 2003. Physical Manifestations of Emotional disorders: Observations from the study of non-ordinary states of consciousness" in Exploring Holotropic breathwork: Selected Articles from a Decade of the Inner Door. Taylor, K [Ed.] Hanford Mead (http://en.wikipedia.org/wiki/Holotropic_Breathwork, retrieved 22-9-08).

Grof, S., \& Bennett, H. 1992. The holotropic mind: the three levels of human consciousness and how they shape our lives. New York: HarperCollins.

Gudat, U. 1997. A therapist's understanding of bioenergetics. http://www.bioenergetic-therapy.com/iibamain/about/Ifrm_about.htm. Retrieved, 8-9-08.

Hayman, R. 1999. A life of Jung. London: Bloomsbury.

Hergenhahn, B.R. 200I. An introduction to the history of psychology. Belmont, CA: Wadsworth/Thomson Learning.

Hiew, C.C., \& Yap, S.Y. 2005. Dynamics of chi-gung healing. Toronto: BookSurge.

lyengar, B.K.S. 2005. Light on life. London: Rodale.

James, W. 1890. Principles of psychology. New York, NJ: Henry Holt.

Jung, C.G. 1916. The Personal and the Collective Unconscious. In The Collected Works of C.G. Jung, Vol 7, pp.127-I37. Trans. R.Hull. Edited by Sir Herbert Read, Fordham, M.; Adler, G.; executive editor, McGuire, W.; Bollingen Series XX, 20 volumes. London: Routledge and Kegan Paul, Princeton: Princeton University Press, 1953-1979. (Henceforth referred to as C.W. with the volume and page numbers).

Jung, C.G. 1917. The concept of the collective unconscious. C.W. 7, 42-53.

Jung, C.G. 193 Ia. Basic postulates of analytical psychology. C.W. 8, 338-357.

Jung, C.G. 193 Ib. Archiac man. C.W. 8, 72-73

Jung, C.G. 1936. Psychology and religion. Yoga and the west. C.W. I I, 529-537

Jung, C.G. 1957. Commentary on "The secret of the golden flower." CW, I3, I-56.

Jung, C.G. 196I. Memories, dreams, reflections. Jaffe. A. (Ed.). New York: Pantheon.

Judith, A. 2004. Eastern body, western mind. Berkeley, Ca: Celestial Arts.

Koestler, A, 1977. Janus: a summing up. London: Hutchinson and Co.

Lan, C., Lai, J. \& Chen, S. 2002. Tai Chi Chuan. An ancient wisdom on exercise and health promotion. Sports Medicine, 32(4), 218-225.

Lowen, A. 1967. The betrayal of the body. London:Collier Books.

Lowen, A. 1976. Bioenergetics. New York: Penguin.

Lowen, A 1990. Spirituality of the body: bioenergetics for grace and harmony. New York: Macmillan.

Loy, D. 2007. Loving the world as one's own body: the nondualist ethics of Taoism, Buddhism, and Deep Ecology. http:// ccbs.ntu.edu.tw/FULL TEXT/JR-MISC/60680.htm. Retrieved I4-6-2007. 
Manne, J. 1999. Only one breath: Buddhist breathwork and the nature of consciousness. The Healing Breath, I(I), 22-46.

Morningstar, J. 1999. Breathwork: Therapy of choice for whom? The Healing Breath, I(I), I0-16.

Myers, L. 1992. Transpersonal psychology: the role of the Afrocentric paradigm (pp. 5-I7). In Burlew, AKH, Banks, WC., McAdoo, HP, Azibo, DA (Eds.) African American Psychology. Theory research and practise. New York: Sage.

Myers, L. 1993. Understanding an Afrocentric worldview: introduction to an optimal psychology. Kendal Hunt: Dubuque.

Pert, C. 1997. Molecules of Emotion: the Science behind mind-body medicine. New York: Touchstone.

Reich, W. 1949. Character analysis. New York: Bantam.

Reich, W. 2008. The Wilhelm Reich Museum at Organon, Maine (http://www.wilhelmreichmuseum.org/biography.html retrieved 9-908).

Reid, D. 1989. The Tao of health, sex and longevity: a modern practical approach to the ancient way. London: Simon and Schuster.

Reid, D. 1993. Guarding the three treasures: the Chinese way of health. London: Simon and Schuster.

Reid, D. 1998. Chi-Gung. Harnessing the power of the universe. London: Simon and Schuster.

Reid, D. 2003. The tao of detox. London: Simon and Schuster.

Rhinewine, J. P. \& Williams, O. J. 2007. Holotropic breathwork: the potential role of a prolonged, voluntary hyperventilation procedure as an adjunct to psychotherapy. Journal of Alternative and Complementary Medicine, I 3(7), 77I-776.

Sherwood, P.M. 2007. Holistic counselling: a new vision for mental health. Bunbury WA: Sophia Publications.

Taylor-Piliae, R.E. \& Froelicher, E.S. 2004. The effectiveness of Tai Chi exercise in improving aerobic capacity: a meta-analysis. Journal of Cardiovascular Nursing, 19 (6), 48-57.

Wilber, K. 1977. The spectrum of consciousness. London: Quest.

Wilber, K. 2000. Integral psychology. Boston: Shambhala.

Wilber, K. 2007. Integral spirituality. Boston: Integral Books. 